\title{
Involvement of GSK-3 $\beta$ Phosphorylation Through PI3-K/Akt in Cerebral Ischemia-Induced Neurogenesis in Rats
}

\author{
Keishi Kisoh ${ }^{1} \cdot$ Hideki Hayashi $^{1} \cdot$ Tsuyoshi Itoh $^{1} \cdot$ Mayumi Asada $^{1} \cdot$ Miho Arai $^{1}$. \\ Bo Yuan ${ }^{1} \cdot$ Kouichi Tanonaka $^{2}$ - Norio Takagi ${ }^{1}$ (D)
}

Received: 28 July 2016 / Accepted: 2 November 2016 / Published online: 19 November 2016

(C) The Author(s) 2016. This article is published with open access at Springerlink.com

\begin{abstract}
Glycogen synthase kinase (GSK)-3 $\beta$, which is abundantly expressed in the central nervous system, regulates various cellular processes including gene expression, cell proliferation, and differentiation. However, involvement of GSK-3 $\beta$ in cerebral ischemia-induced endogenous neurogenesis is not yet fully understood. Appropriate strategies to prevent ischemic cell damage and subsequent severe sequelae are needed. The purpose of the present study was to determine the relationship between pathophysiological alteration of the GSK- $3 \beta$ signaling pathway and cerebral ischemia-induced endogenous neurogenesis in rats. Severe cerebral ischemia was produced by the injection of 700 microspheres into the right internal carotid artery of rats. We demonstrated that phosphorylation of GSK-3 $\beta$ at its Ser9 and that of Akt was significantly enhanced on day 7 after the cerebral ischemia, as was the number of NeuroD-positive cells. Treatment with a phosphatidylinositol 3-kinase (PI3-K) inhibitor decreased the cerebral ischemia-induced phosphorylation of Akt and that of GSK-3 $\beta$ at its Ser9. In addition, as the protein levels of insulin-like growth factor-1 (IGF-1) and brain-derived neurotrophic factor (BDNF) were decreased, they might not have been essential for activation of the PI3-K/Akt/GSK-3 $\beta$ pathway after severe cerebral ischemia. Although it remains to be
\end{abstract}

Norio Takagi

takagino@toyaku.ac.jp

1 Department of Applied Biochemistry, Tokyo University of Pharmacy and Life Sciences, 1432-1 Horinouchi, Hachioji, Tokyo 192-0392, Japan

2 Department of Molecular and Cellular Pharmacology, Tokyo University of Pharmacy and Life Sciences, 1432-1 Horinouchi, Hachioji, Tokyo 192-0392, Japan determined what factors activate this pathway, our results suggest that PI3K/Akt-dependent GSK-3 $\beta$ signaling and subsequent expression of NeuroD were involved in the neurogenesis elicited by cerebral ischemia.

Keywords Cerebral ischemia $\cdot$ Neurogenesis · GSK-3 $\beta$ . PI3-K/Akt

\section{Introduction}

Glycogen synthase kinase-3 (GSK-3), a serine/threonine (Ser/Thr) kinase, was identified some time ago as an enzyme that phosphorylates glycogen synthase to render it inactive [1]. There are two isoforms of it, i.e., $\alpha$ and $\beta$. GSK-3 $\beta$ is abundantly expressed in the mammalian central nervous system and regulates various cellular processes including gene expression, cell proliferation, and differentiation. $\beta$-Catenin is a signaling molecule that is phosphorylated by GSK-3 $\beta$, resulting in its degradation by the ubiquitin-proteasome system. Thus, inactivated GSK-3 $\beta$, which is phosphorylated at its Ser9, inhibits this proteasomal degradation of $\beta$-catenin. As a result, $\beta$-catenin accumulates in the cytosol and is translocated into the nucleus, where it contributes to gene expression related to cell proliferation and differentiation $[2,3]$. Therefore, $\beta$-catenin has been implicated in the maintenance of the stem cell pool [4], neuronal differentiation [5], and the development of the central nervous system [6]. NeuroD, which is a proneural basic helix-loop-helix (bHLH) transcription factor, promotes premature cell cycle exit and differentiation into neural progenitor cells, indicating a differentiation factor $[7,8]$. Its expression is regulated by $\beta$-catenin [9]. Some studies have indicated that NeuroD is also 
involved in not only embryonic neurogenesis but also in postnatal neurogenesis [10, 11]. Furthermore, environmental signals regulate adult neurogenesis, at least in part, through the activation of NeuroD [12, 13].

It has been shown that neurogenesis occurs in two restricted areas of the brain, i.e., the subventricular zone of the lateral ventricles and subgranular zone (SGZ) of hippocampal dentate gyrus, throughout life [14]. Furthermore, the existence of additional stem cell niches for neurogenesis was demonstrated, such as the substantia nigra, circumventricular organs located along the ventricular midline, and the walls of the third and fourth ventricles [15-17]. The process of neurogenesis is closely related to neurological functions involving spatial learning, memory, and behavioral response [18] and is regulated by various factors such as age, drugs, disease, and the environment. Indeed, anti-depressants improve depression symptoms, and there is a correlation between their use and restoration of impaired neurogenesis in the hippocampus [19]. Cerebral ischemia also enhances neurogenesis [20-22]. In addition, it has been implied that neurons newly generated after cerebral ischemia migrate to the injured area $[23,24]$ and replace the injured or dead neurons [20]. Some of these cells might be integrated into the existing neural network or form new ones. Therefore, acceleration of endogenous neurogenesis in the brain has been expected as new therapeutic approach for cerebral ischemia. However, it has been shown that the majority of newly generated endogenous neurons fail to survive. Rather, neural stem/progenitor cells without proliferation activity secrete autocrine and/or paracrine factors to maintain the multipotency in the central nervous system [25]. Furthermore, neural stem cells, when transplanted into lesion sites in an injured spinal cord, have the ability to increase the expression of neurotrophic factors [26, 27]. In this sense, we demonstrated previously that the injection of neural progenitor cells (NPCs), which were isolated by using the neurosphere method, results in improvement of spatial learning dysfunction and post-stroke depression $[28,29]$. However, the pathophysiological alterations leading to cerebral ischemia-induced endogenous neurogenesis are not fully understood. Therefore, it is important to investigate the pathophysiological environment underlying cerebral ischemia-induced neurogenesis for appropriate therapies for stroke. Elucidating the regulation of endogenous neurogenesis in cerebral ischemia may lead to a further understanding of the pathophysiology of stroke and the development of new therapeutic targets. The aim of this study was to determine the relationship between pathophysiological alteration of the GSK-3 $\beta$ signaling pathway and the initial stages of cerebral ischemia-induced endogenous neurogenesis in rats.

\section{Materials and Methods}

\section{Animal Surgical Procedures}

Male Wistar rats weighing 220-250 g (Charles River Japan Inc., Tsukuba, Japan) were used. The rats were maintained at $23 \pm 1{ }^{\circ} \mathrm{C}$ in a room with a constant humidity of $55 \pm 5 \%$ and a light cycle of 12-h light/12-h darkness. The rats had free access to food and water according to the National Institute of Health Guide for the Care and Use of Laboratory Animals and the Guidance for Experimental Animal Care issued by the Prime Minister's Office of Japan. The study was approved by the Committee of Animal Care and Welfare of Tokyo University of Pharmacy and Life Sciences. Microsphereinduced cerebral embolism (ME) was performed by the method described previously [30]. Anesthesia was induced with $4 \%$ isoflurane and maintained with $2.5 \%$ isoflurane. The right external carotid and pterygopalatine arteries were temporarily occluded with strings. Immediately thereafter, a needle connected to a polyethylene catheter (TORAY Feeding Tube, Chiba, Japan) was inserted into the right common carotid artery. Next, 700 microspheres $(45.0 \mu \mathrm{m}$ in diameter; Polysciences Inc., Warrington, PA, USA), suspended in $20 \%$ dextran solution $(150 \mu \mathrm{l})$, were injected over a 20 -s period into the right internal carotid artery through the cannula. After the injection, the needle was removed, and the puncture wound was then repaired with surgical glue. Sham-operated rats received the same volume of vehicle without microspheres. Non-operated rats were used as naïve control rats in the present study. As described in earlier reports [31, 32], scattered necrotic areas, variable in size and shape, were seen mainly in the parietotemporal cortex, corpus callosum, hippocampus, thalamus, and lenticular nucleus of the ipsilateral hemisphere after microsphere embolism. In the present study, $41 \mathrm{ME}$ rats were prepared for experiments. Among these rats, 6 of them (14.6\%) died within 3 days after the operation. Twenty-five sham-operated rats survived throughout the experiments.

Wortmannin (Sigma-Aldrich, Inc. MO, USA), which is a potent and selective inhibitor of phosphatidylinositol 3-kinase (PI3-K; $\mathrm{IC}_{50}=2 \mathrm{nM}$; [33]), was dissolved in dimethyl sulfoxide and injected intravenously, as previously reported [34, 35], on days 5 and 6 after ME. For tissue sampling for Western blotting and histochemical analysis, wortmannin-untreated and wortmannin-treated cerebral ischemic rats were sacrificed on day 7 after surgery. The dose used in the present study was based on the data obtained in our preliminary study: the effect of treatment with $30 \mu \mathrm{g} / \mathrm{kg}$ wortmannin on phosphorylation of Akt was more stable than that with 15 or $100 \mu \mathrm{g} / \mathrm{kg}$.

\section{Western Immunoblotting}

Rats were sacrificed by decapitation on days $1,3,7$, and 14 day after surgery for cerebral ischemia- or sham-operated 
rats $(n=5$ each). To determine the effects of wortmannin on the phosphorylation of Akt, wortmannin-treated cerebral ischemic rats were sacrificed by decapitation on day 7 after surgery $(n=5)$. The ipsilateral hemisphere was homogenized in ice-cold buffer containing $320 \mathrm{mM}$ sucrose, protease inhibitors, and phosphatase inhibitor cocktail (Roche Diagnostics Co.) at $4{ }^{\circ} \mathrm{C}$. The homogenate was centrifuged at $1000 \mathrm{~g}$ for $10 \mathrm{~min}$ at $4{ }^{\circ} \mathrm{C}$. The supernatant was then collected and subsequently centrifuged at $12,000 \mathrm{~g}$ for $20 \mathrm{~min}$. After this second centrifugation, the supernatant was collected and centrifuged at $100,000 \mathrm{~g}$ in a TLA120.2 rotor (Beckman Coulter) for $60 \mathrm{~min}$ at $4{ }^{\circ} \mathrm{C}$. After centrifugation, the supernatant was collected and used as the cytosolic fraction. Western blotting using total homogenate and cytosolic fraction was performed according to standard protocols. The following primary antibodies were used: rabbit monoclonal anti-phospho-GSK-3 $\beta$ (Ser 9; Cat. No. 5558, Cell Signaling Technology Inc., Danvers, MA, USA), mouse monoclonal anti-phosphoGSK-3 $\alpha / \beta$ (Tyr 279/Tyr 216; Cat. No. 05-413, Upstate Biotechnology Inc.), rabbit monoclonal anti-GSK-3 $\beta$ (Cell Signaling), rabbit monoclonal anti-phospho-Akt (Cell Signaling), rabbit monoclonal anti-Akt (Cat. No. 4691, Cell Signaling), rabbit polyclonal anti-phospho- $\beta$-catenin (Cat. No. 9561, Cell Signaling), mouse monoclonal anti- $\beta$-catenin (Cat. No. ab6301; Abcam, Minneapolis, MN, USA), goat polyclonal anti-NeuroD (Cat. No. SC-1084, Santa Cruz), mouse monoclonal anti-GAPDH (Cat. No. MAB374, Millipore, Massachusetts, USA), rabbit polyclonal antibrain-derived neurotrophic factor (BDNF; Cat. No. SC-546, Santa Cruz), rabbit polyclonal anti- insulin-like growth factor1 (IGF-1; Cat. No. SC-9013, Santa Cruz), and mouse monoclonal anti- $\beta$-actin (Cat. No. A1978, Sigma-Aldrich) antibody. Subsequently, the protein blots were washed and incubated with the appropriate secondary antibodies. Bound antibodies were detected by the enhanced chemiluminescence method (Amersham Biosciences Inc., Piscataway, NJ, USA). Quantification was performed by using computerized densitometry (LuminographII, ATTO Co., Tokyo, Japan) and an image analyzer (CS Analyzer, ATTO Co., Tokyo, Japan).

\section{Immunohistochemistry}

On day 7 after surgery, wortmannin-untreated $(n=5)$ and wortmannin-treated $(n=5)$ cerebral ischemic rats were perfused via the heart with $4 \%$ paraformaldehyde in $0.1 \mathrm{M}$ phosphate buffer. The brains were quickly removed and immersed in 30\% sucrose in $0.1 \mathrm{M}$ phosphate buffer. They were then cut into 5-mm-thick coronal slabs, which were subsequently embedded in Neg50 (Richard-Allan Scientific, Kalamazoo, MI, USA) and cut into $20-\mu \mathrm{m}$ sections with a cryostat. For immunostaining, sections were incubated overnight with the desired primary antibody at $4{ }^{\circ} \mathrm{C}$ after blocking, and then with the corresponding secondary antibody for $1 \mathrm{~h}$ at $25^{\circ} \mathrm{C}$. In the case of double immunofluorescence staining, after a wash, the same section was incubated overnight with another primary antibody at $4{ }^{\circ} \mathrm{C}$. Subsequently, it was incubated with the corresponding secondary antibody for $1 \mathrm{~h}$ at $25{ }^{\circ} \mathrm{C}$. Omission of primary antibodies served as a negative control. No immunostaining was detected in this group. The following primary antibodies were used: mouse monoclonal anti-Ki67 (Cat. No. 556003, BD Bioscience, San Jose, USA), goat polyclonal anti-doublecortin (DCX) (Cat. No. SC-8066, Santa Cruz Biotechnology Inc., Santa Cruz, CA, USA), or goat polyclonal anti-NeuroD (Cat. No. SC-1084, Santa Cruz) antibody. The secondary antibodies used were as follows: Alexa Fluor 488-labeled donkey anti-mouse IgG (Molecular Probes Inc., Eugene, OR, USA) and Alexa Fluor 594-labeled donkey anti-goat $\operatorname{IgG}$ antibodies (Molecular Probes Inc.). Fluorescence was detected by using an Olympus fluorescence microscope (IX-71; Olympus). Fluorescent images were loaded into the MetaMorph software program (Molecular Devices, Downingtown, PA). Based on background fluorescence and the size of their nucleus, NeuroD-labeled cells in the SGZ and granule cell layer (GCL) of the hippocampal dentate gyrus were counted by use of the MetaMorph software program in five sections per animal, which areas corresponded to coronal coordinates of -3.14 to -4.52 from bregma.

\section{Statistical Analysis}

The results were expressed as the means \pm standard error of the mean (SEM). Differences between two groups were evaluated statistically by use of the unpaired Student's $t$ test. Statistical comparison among multiple groups was evaluated by analysis of variance (ANOVA), followed by Bonferroni test as a post hoc test. $P$ values of less than 0.05 were considered significant.

\section{Results}

\section{GSK-3 $\beta / \beta-$-Catenin Signaling Pathway After ME}

It is known that GSK-3 $\beta$ is inactivated by phosphorylation at its Ser9 and activated by that at its Tyr216. We first determined the time course of changes in phosphorylation levels of GSK-3 $\beta$ at Ser9 as well as at Tyr216 in the hemispheres after surgery. The phosphorylation level of GSK-3 $\beta$ at Ser9 of ME-operated rats was significantly increased compared with that of shamoperated rats on day 7 (Fig. 1a). In contrast, there were no significant differences in phosphorylation level of GSK-3 $\beta$ at Tyr216 between sham- and ME-operated rats throughout the experiment (Fig. 1b). Normally, $\beta$ catenin is phosphorylated by GSK-3 $\beta$ in the cytosol and is degraded by the ubiquitin-proteasome pathway. As 

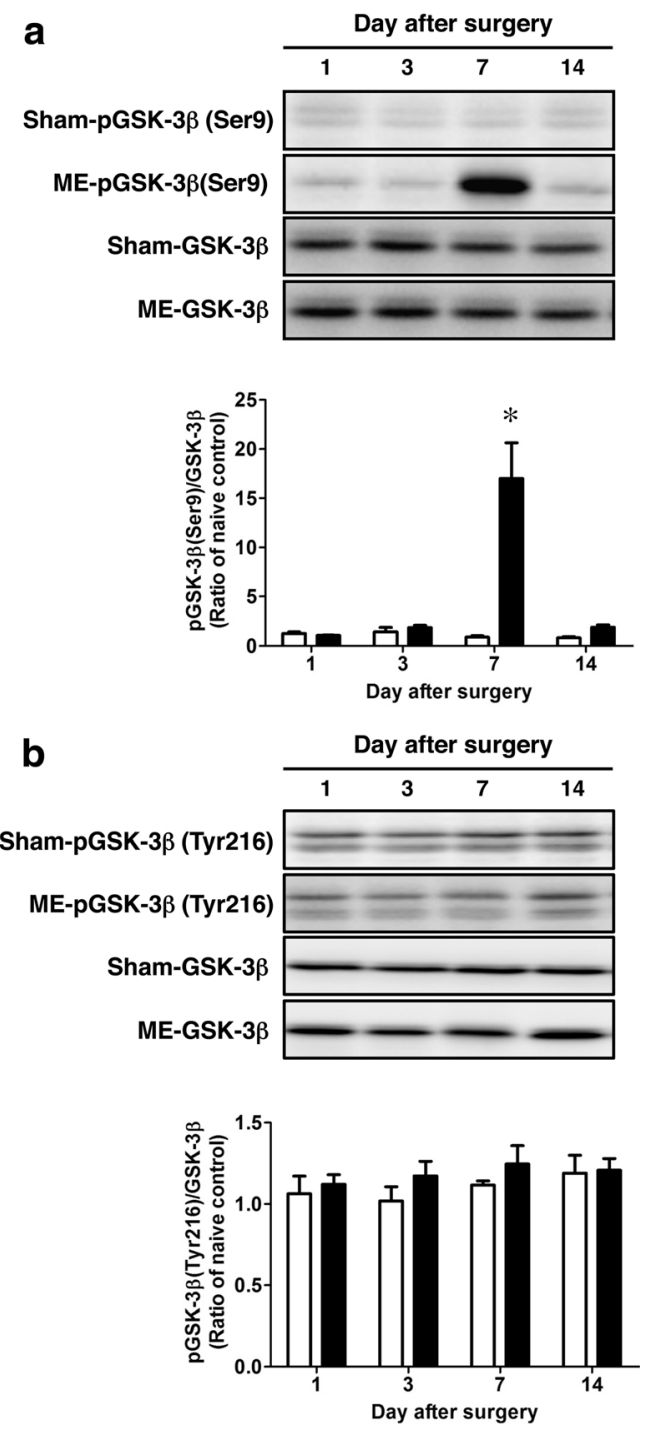

Fig. 1 Time course of changes in the levels of phosphorylated GSK-3 $\beta$ after cerebral ischemia. a Time course of changes in the phosphorylation of GSK-3 $\beta$ at its Ser9 and total levels of GSK-3 $\beta$ in the sham- (sham; white bars) and ME-operated (ME; black bars) on days 1, 3, 7, and 14 after surgery. Bands corresponding to phosphorylated GSK-3 $\beta$ at Ser9 (pGSK-3 $\beta$ [Ser9]) and total GSK-3 $\beta$ (GSK-3 $\beta$ ) were scanned, and the scanned bands were normalized by total GSK- $3 \beta$ on the same blot. b Time course of changes in the phosphorylation of GSK-3 $\beta$ at its Tyr216 and total levels of GSK-3 $\beta$ in the sham- (sham) and ME-operated (ME) on days $1,3,7$, and 14 after surgery. Bands corresponding to phosphorylated GSK-3 $\beta$ at its Ser9 (pGSK-3 $\beta$ (Ser9)) and total GSK$3 \beta$ (GSK-3 $\beta$ ) were scanned, and the scanned bands were normalized by total GSK-3 $\beta$ on the same blot. Results are expressed as the mean ratio of the ME group to the non-operated (naïve) group $\pm \operatorname{SEM}(n=5$ each). *Significant difference from the sham-operated group $(p<0.05)$

GSK-3 $\beta$ was inactivated by marked phosphorylation at Ser9 on day 7 after ME, we next examined the phosphorylation level of $\beta$-catenin in the cytosolic fraction. Only on day 7 after ME, the phosphorylation level of $\beta$-catenin was decreased relative to that of shamoperated control (Fig. 2a). It is known that GSK-3 $\beta$ at Ser9 is phosphorylated by Akt [36]. Next, to examine
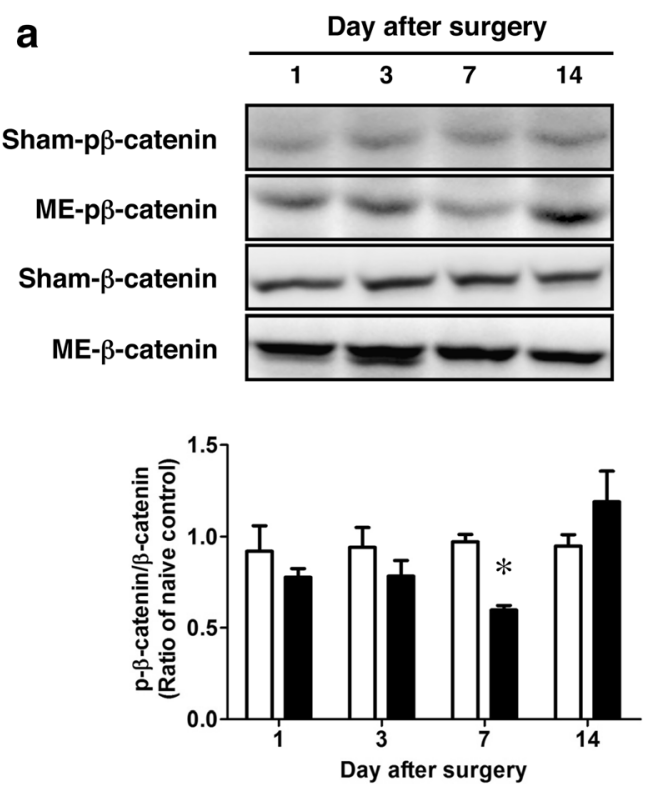

b
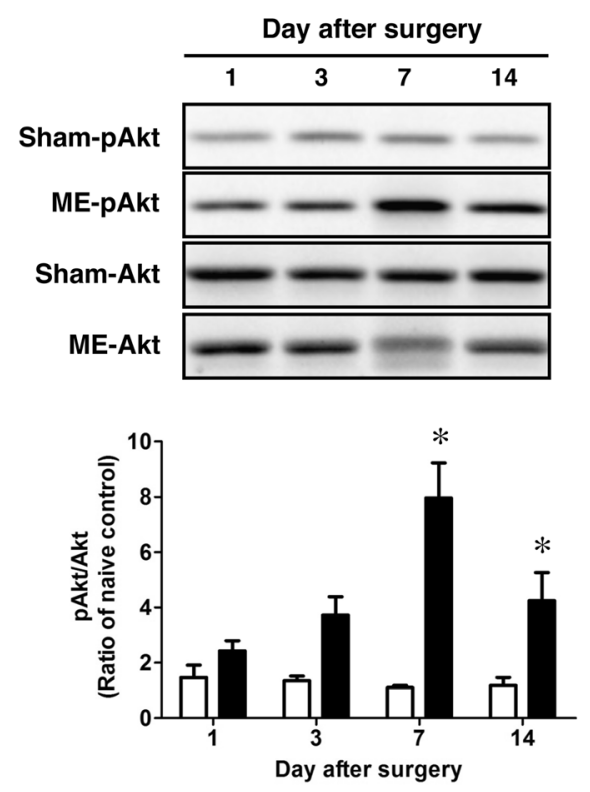

Fig. 2 Time course of changes in the levels of phosphorylated $\beta$-catenin after cerebral ischemia. a Time course of changes in the phosphorylation of $\beta$-catenin and total levels of $\beta$-catenin in the sham- (sham; white bars) and ME-operated (ME; black bars) on days 1, 3, 7, and 14 after surgery. Bands corresponding to phosphorylated $\beta$-catenin ( $\mathrm{p} \beta$-catenin) and total $\beta$-catenin were scanned, and the scanned bands were normalized by total $\beta$-catenin on the same blot. b Time course of changes in the phosphorylation of Akt and total levels of Akt in the sham- (sham) and ME-operated (ME) on days 1, 3, 7, and 14 after surgery. Bands corresponding to phosphorylated Akt (pAkt) and total Akt were scanned, and the scanned bands of pAkt were normalized by total Akt on the same blot. Results are expressed as the mean ratio of the ME group to the non-operated (naïve) group $\pm \operatorname{SEM}(n=5$ each). *Significant difference from the sham-operated group $(p<0.05)$

the upstream of phosphorylated GSK-3 $\beta$, we assessed the time course of changes in the level of phosphorylated Akt. Phosphorylation of Akt at its Ser473, which activates the enzyme, after ME gradually increased as 
Fig. 3 Enhancement of cell proliferation and differentiation in the hippocampal dentate gyrus on day 7 after cerebral ischemia. a, $\mathbf{b}$ Cells in the dentate gyrus were stained with Hoechst 33342 (Hoechst). b, f Ki67-positive cells in the SGZ of the ipsilateral dentate gyrus of sham-operated (b) and ME (f) rats. c, g Ki67positive cells (green) expressed a marker for immature neuron (DCX; red). d, h Images of double staining (merge) with Ki67 (green, b, f) and DCX (red, c, g). i Image of double staining with Ki67 and DCX in " $\mathrm{H}$ " is enlarged. Scale bar, 200 and

$50 \mu \mathrm{m}$ (in enlargement)
Sham 7 ME7
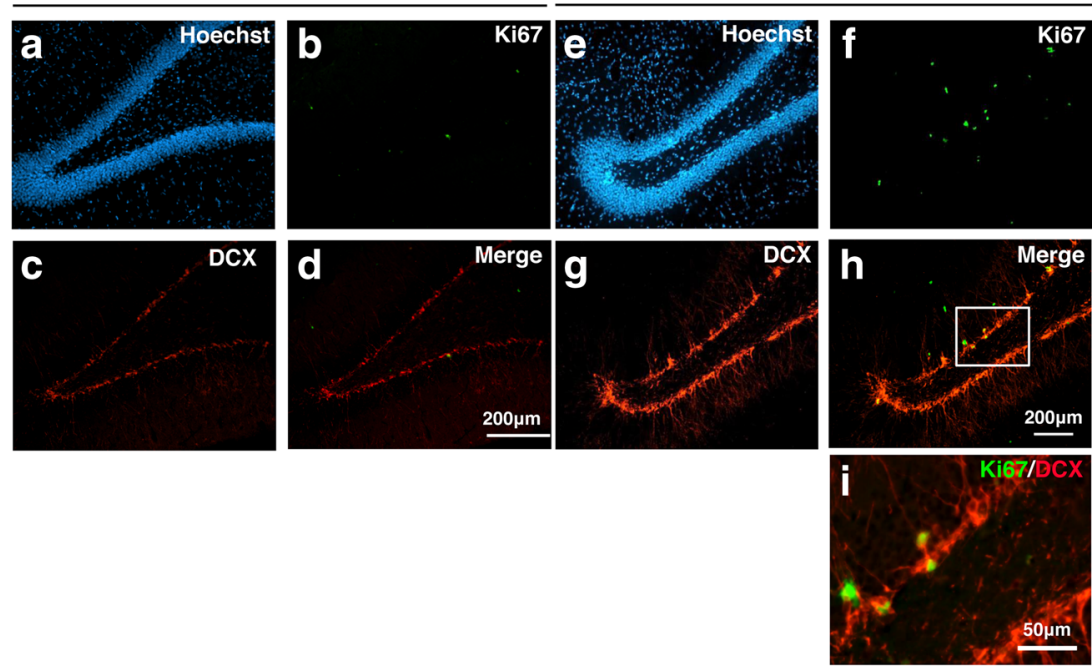

compared with that of sham-operated rats up to day 7 (Fig. 2b). The increased phosphorylation of Akt at Ser473 remained on day 14 after ME. The greatest increase was seen on day 7 after ME (Fig. 2b).

\section{Cell Proliferation and Differentiation After ME}

The GSK- $3 \beta / \beta$-catenin signaling pathway is associated with the expression of NeuroD, which plays an important role in neural differentiation. We therefore determined cell proliferation and differentiation in the hippocampal dentate gyrus on day 7 after ME at the same time period during which the phosphorylation of GSK-3 $\beta$ at Ser9 was significantly increased. We initially performed immunostaining using Ki67 antibody, a marker of proliferating cells, to confirm cell proliferation after ME. Ki67-positive cells were detected in the hippocampal dentate gyrus, and their number was increased in the ipsilateral dentate gyrus (Fig. 3e, f) compared with that in the sham-operated rats (Fig. 3a, b). Next, to determine whether the proliferating cells differentiated into neurons, we examined the expression of a neural marker in these Ki67-positive cells. Ki67positive cells expressed DCX, a marker for immature neurons, on day 7 after ME (Fig. 3c-i). Furthermore, the expression of NeuroD, which plays an important role in neural differentiation, was enhanced in the ipsilateral dentate gyrus after ME (Fig. 4d-f) compared with that in the sham-operated rats (Fig. 4a-c). This increase in the number of NeuroD-positive cells was detected in the ipsilateral dentate gyrus on day 7 after ME (Fig. 4g). Immunoblotting analysis also showed that the level of NeuroD after ME was significantly increased compared with that of sham-operated rats (Fig. 4h-i).

We next assessed the effect of wortmannin, an inhibitor of PI3-K, on the phosphorylation of Akt and GSK-3 $\beta$ on day 7 after ME. The increased phosphorylation of Akt after ME was almost completely suppressed by the treatment with wortmannin (Fig. 5a). Also, the marked increase in phosphorylation of GSK-3 $\beta$ on its Ser9 after ME was attenuated by the wortmannin treatment (Fig. 5b). In contrast, phosphorylation of GSK-3 $\beta$ on Tyr 216 was not affected by ME regardless of treatment or not with this inhibitor (Fig. 5c). Furthermore, the decreased phosphorylation of $\beta$-catenin was attenuated by treatment with wortmannin (Fig. 5d). To determine whether the Akt/GSK-3 $\beta$ signaling pathway contributed to neurogenesis via the expression of NeuroD, we next examined the effect of wortmannin on the number of NeuroD-positive cells in the hippocampal dentate gyrus on day 7 after ME. The number of NeuroD-positive cells in ME rats treated with wortmannin was lower than that of those in untreated ME rats (Fig. 6).

\section{Possibility of Involvement of IGF-1 and BDNF in GSK-3 $\beta$ Signaling After ME}

We next hypothesized that some growth factors are involved in the altered Akt-GSK- $3 \beta$ - $\beta$-catenin signaling pathway after ME. Therefore, we investigated the expression of IGF-1 and BDNF on day 7 after the operation. The expression levels of IGF-1 (Fig. 7a) and BDNF (Fig. 7b) in ME-operated rats were significantly decreased compared with those of the shamoperated rats (Fig. 7).

\section{Discussion}

In previous studies, we demonstrated that ME increased proliferation of cells that expressed nestin, a neural progenitor marker, and DCX, a microtubule-associated protein found in migrating immature neurons. Furthermore, a few proliferated 

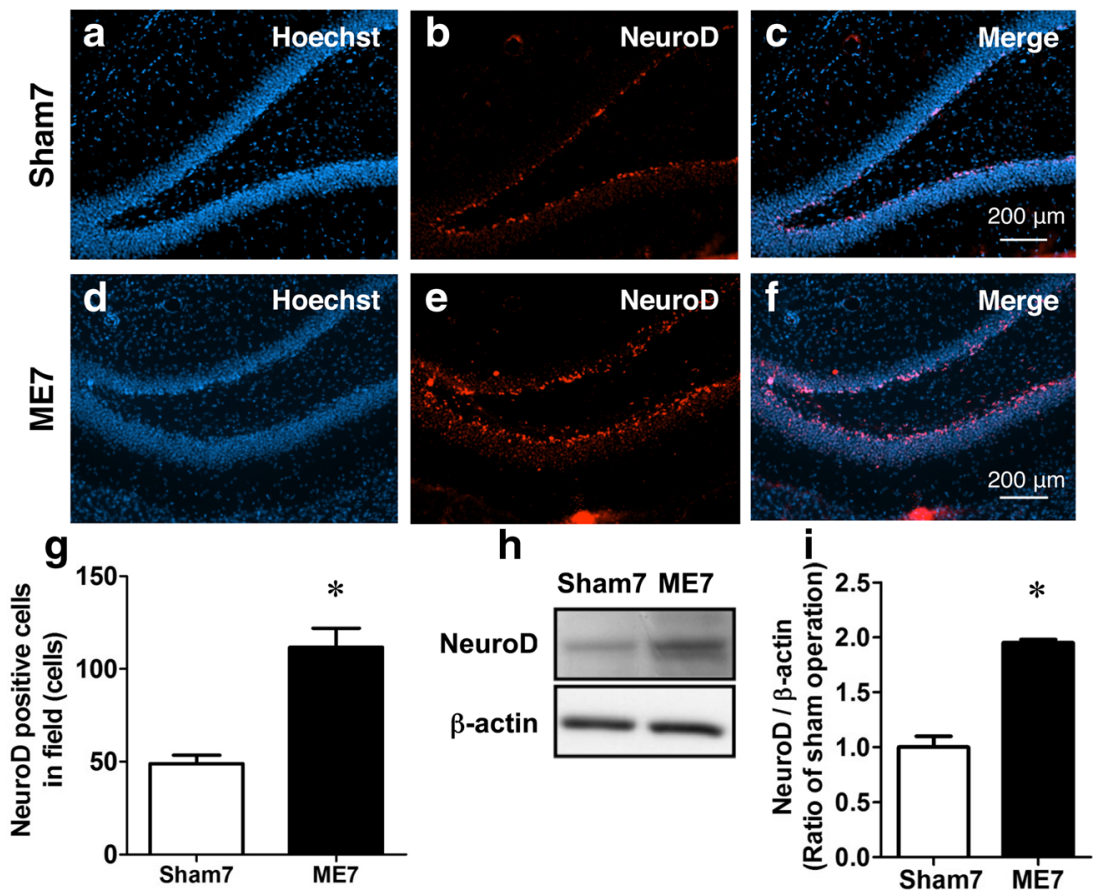

Fig. 4 Increase in the number of NeuroD-positive cells after cerebral ischemia. Images of double staining (merge, c, f) with Hoechst 33342 (Hoechst, a, d) and for NeuroD (red, b, e) in the ipsilateral hippocampal dentate gyrus on day 7 after sham $(\mathbf{a}-\mathbf{c})$ and cerebral ischemia $(\mathbf{d}-\mathbf{f})$. Scale bar, $200 \mu \mathrm{m}$. $\mathrm{g}$ The number of NeuroD-positive cells in the ipsilateral SGZ of sham-operated (Sham7) and ME-operated (ME7) rats on day 7 after surgery. Values for NeuroD-positive cells are represented as the mean \pm SEM. *Significant difference from the sham-operated group

cells expressed MAP2, a neural marker, whereas GFAP was not expressed on day 28 [37]. These data imply that ME promoted cell proliferation, migration, and differentiation into neurons. However, the maximum increase in the number of proliferating cells on day 7 after ME decreased with time [37, 38]. We have also demonstrated a series of behavioral tests, including motor, sensory, reflex, and balance tests, on days 1 , 7, 14, 21, and 28 after ME according to the modified neurological severity scores (mNSS) [29]. There was a significant reduction in the score of ME rats. Furthermore, we performed the sucrose preference test (SPT) and forced-swimming test (FST) as measures of post-stroke depression (PSD)-like behavior [29]. In that study, the sucrose preference of ME rats decreased at 7 days after surgery, and this decrease was sustained at least until day 28. As a decrease in sucrose consumption indicates a state of anhedonia, a core symptom of depression, we suggested that our results could be used to estimate mood disturbance of rats after ME. Furthermore, the immobility time in the FST was prolonged in ME rats [29]. These results suggested that ME-induced cerebral ischemia affected behaviors associated with depression. On the basis of our previous studies, the primary objective of the present study was to determine the intracellular signaling, including GSK pathways, in the initial stages of cerebral

ischemia-induced neurogenesis for a further understanding of the pathophysiology of stroke, correlation between neurological dysfunction and ischemia-induced neurogenesis, and the development of new therapeutic targets.

GSK- $3 \beta$ phosphorylates many substrates and is involved in various cellular processes. Of these, $\beta$-catenin is phosphorylated by GSK- $3 \beta$, leading to degradation of the former by the ubiquitin-proteasome system, whereas non-phosphorylated $\beta$-catenin in the cytosol is translocated to the nucleus, where it acts as transcriptional factor to promote the expression of NeuroD [9]. In the present study, the inactivation of GSK-3 $\beta$ induced by phosphorylation at its Ser9 was significantly enhanced in particular on day 7 after ME. In contrast, there were no changes in the phosphorylation of GSK-3 $\beta$ at Tyr216 compared with that of in the sham-operated group throughout the experiment. Changes in activity of GSK- $3 \beta$ depend on the region of the injury and the severity of brain ischemia models $[39,40]$. Although neurogenesis is regulated by various signaling pathways, the ability of GSK-3 $\beta$ to play an important role in adult neurogenesis has been observed [41, 42]. For example, lithium, a GSK-3 $\beta$ inhibitor, increases adult neurogenesis in rodents [43]. Akt is known to phosphorylate GSK-3 $\beta$ at Ser 9 [36]. Thus, inactivation of GSK-3 $\beta$ by phosphorylation at its Ser9 after ME might be associated with Akt 
a
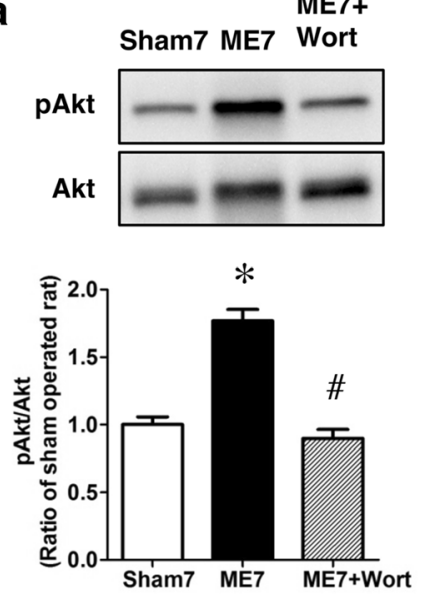

C
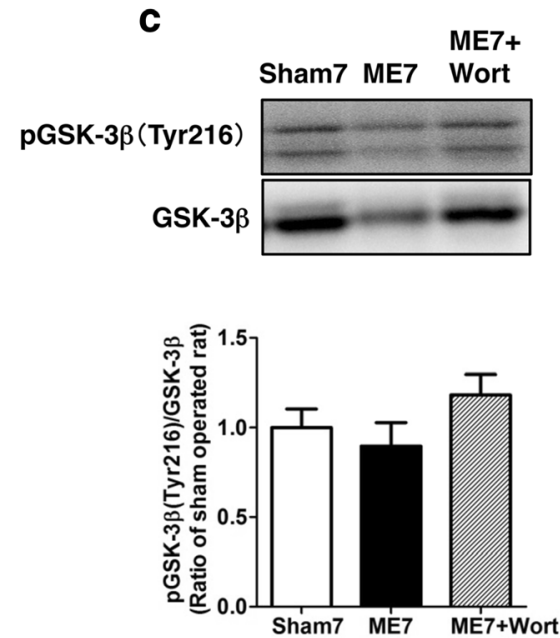

Fig. 5 Effects of wortmannin on GSK-3 $\beta$ signaling. Effects of wortmannin on the phosphorylation of Akt (a), GSK-3 $\beta$ (Ser9; b), GSK-3 $\beta$ (Tyr216; c), and $\beta$-catenin (d) on day 7. Proteins from shamoperated (Sham7) and ME rats on day 7 without (ME7) or with wortmannin (ME7 + Wort) were subjected to immunoblotting with antiphospho-Akt (pAkt), anti-phospho-GSK-3 $\beta$ at Ser9 (pGSK-3 $\beta$ [Ser9]), anti-phospho-GSK-3 $\beta$ at Tyr216 (pGSK-3 $\beta$ [Tyr216]), or anti-phospho$\beta$-catenin ( $p \beta$-catenin) antibody. The blots were then stripped and re-

activation. Indeed, we demonstrated that Akt phosphorylation was enhanced on day 7 after ME. These results raise the possibility that Akt/GSK-3 $\beta / \beta$-catenin signaling might have been enhanced after $\mathrm{ME}$ and contributed to neurogenesis via the expression of NeuroD.

To further determine the possible involvement of AktGSK-3 $\beta$ signaling pathways in ischemia-induced neurogenesis, we examined the effect of wortmannin, an inhibitor of the PI3-K/Akt pathway, on phosphorylation levels of Akt and GSK-3 $\beta$, as well as on the expression of NeuroD. Treatment with wortmannin decreased the levels of phosphorylated of Akt and GSK-3 $\beta$ on its Ser9 without causing any change in phosphorylation on Tyr216 on day 7 after ME. The number of NeuroD-positive cells treated with wortmannin
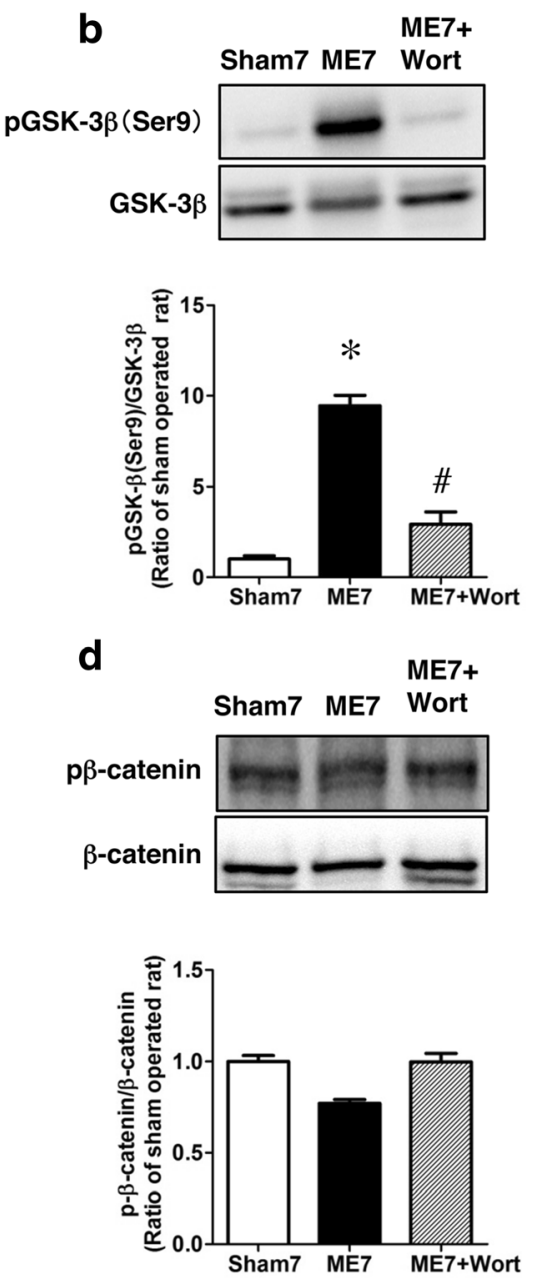

probed with anti-Akt, GSK-3 $\beta$, or $\beta$-catenin antibody. Bands corresponding to phosphorylated forms and non-phosphorylated forms were scanned, and the scanned bands of phosphorylated proteins were normalized by non-phosphorylated proteins on the same blot. Results are expressed as the mean ratio of the ME group to the sham-operated group $\pm \operatorname{SEM}(n=5$ each). *Significant difference from the shamoperated group $(p<0.05)$. "Significant difference from the MEoperated group $(p<0.05)$

tended to be lower than that in the untreated control group. Our results suggest that this PI3-K-dependent Akt/GSK-3 $\beta$ / $\beta$-catenin signaling pathway was, at least in part, associated with the expression of NeuroD after severe cerebral ischemia. In accordance with our previous studies [37, 44], cerebral ischemia-induced cell proliferation was enhanced, and DCX, an immature neural marker, was expressed in the proliferating cells in the present study. These responses were accompanied by an increased number of NeuroD-positive cells in the ipsilateral dentate gyrus. Neurod1-null mice die perinatally from neonatal diabetes [45]. In addition, NeuroD-deficient neurons also die prematurely in the early stage of neurogenesis [46], suggesting that NeuroD is indispensable for neuronal differentiation and maturation at the developmental stage and for 
Fig. 6 Decrease in the number of NeuroD-positive cells by treatment with wortmannin. $\mathbf{a}-\mathbf{f}$ Images of double staining (merge, c, f) with Hoechst 33342

(Hoechst, a, d) and NeuroD (red, b, e) in the ipsilateral

hippocampal dentate gyrus on day 7 after ME with wortmannin treatment (d, e, f). Scale bar, $200 \mu \mathrm{m}$. g Number of NeuroDpositive cells in the ipsilateral SGZ on day 7 after ME without (ME7) or with wortmannin (ME7 + Wort). Values for NeuroD-positive cells are presented as the mean $\pm \mathrm{SEM}$ ( $n=6$ each). *Significant difference from the ME-operated group $(p<0.05)$
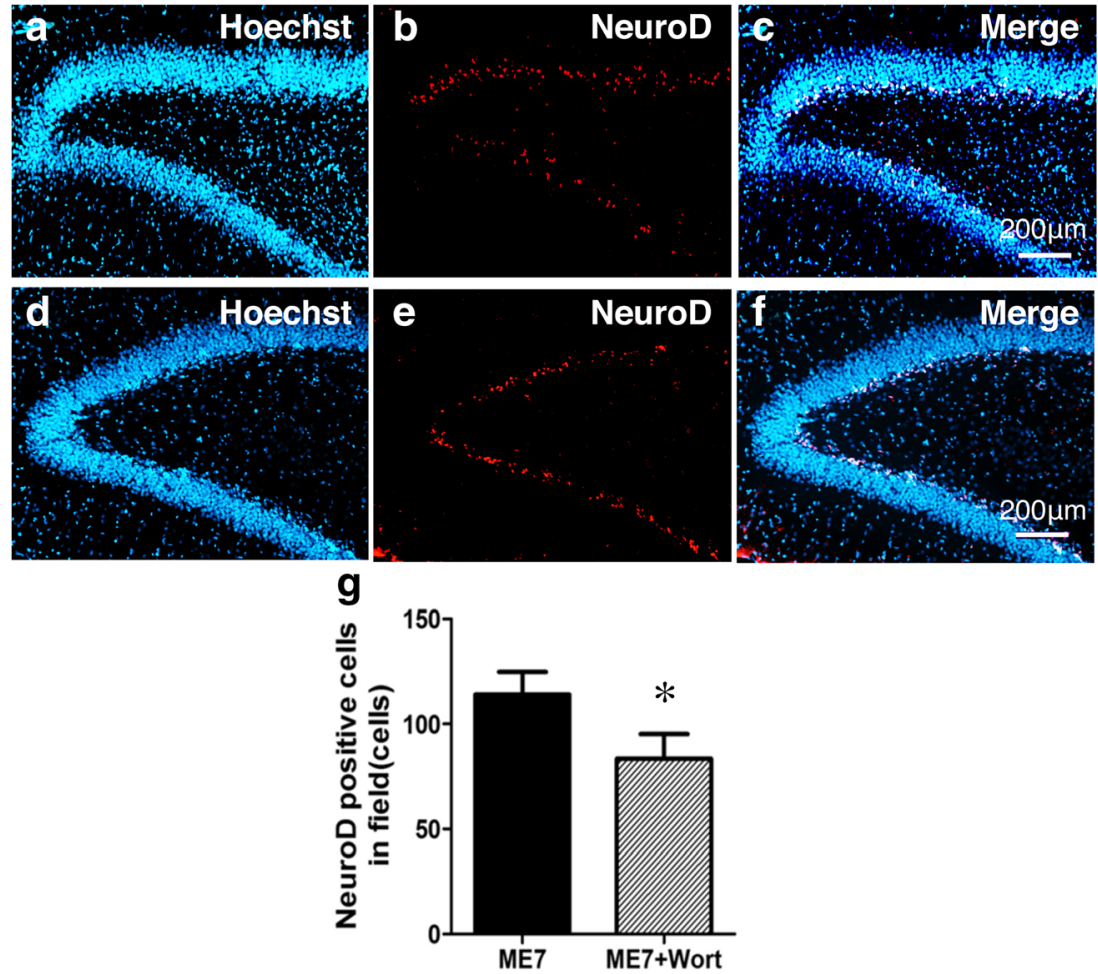

maintenance of progenitor cells. This view is consistent with the finding that conditional deletion of NeuroD1 leads to a decrease in the number of progenitors/immature neurons in the adult brain [10].

As described above, neurogenesis is regulated by various factors such as the environment, growth factors, and neurotransmitters [47-49]. Among considerable factors as important regulators of neurogenesis, it is well known that
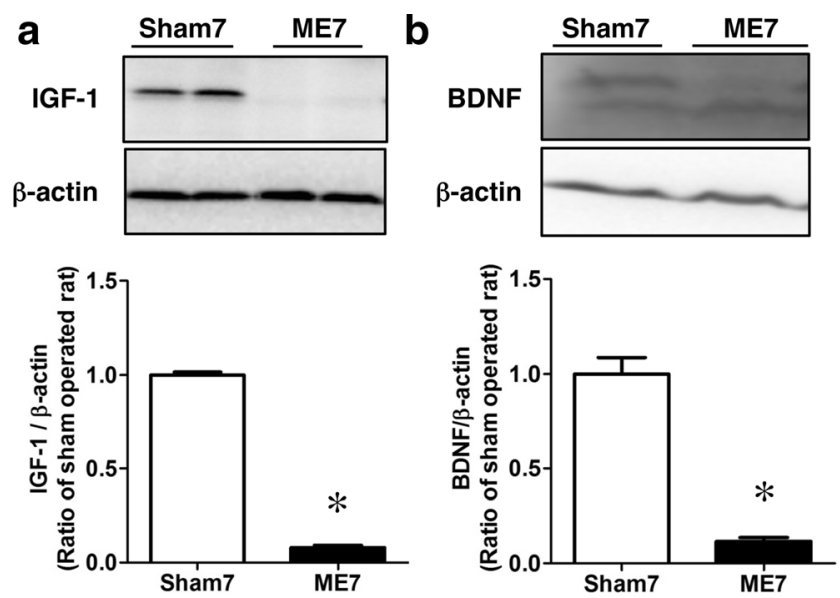

Fig. 7 Changes in the levels of IGF-1 and BDNF after cerebral ischemia. Immunoblotting analysis for the level of IGF-1 (a) or BDNF (b) protein in the sham- (Sham7) and ME-operated (ME7) on day 7 after surgery. Bands corresponding to IGF-1 and BDNF were scanned, and the scanned bands were normalized by $\beta$-actin on the same blot. Results are expressed as the mean ratio of the ME group to the sham-operated group \pm SEM $(n=5$ each). *Significant difference from the sham-operated group $(p<0.05)$ some growth factors are involved in adult neurogenesis. IGF-1 plays a crucial role in neurogenesis $[50,51]$. The stimulation of cells by IGF-1 causes the inactivation of GSK-3 $\beta$ through a PI3-K-dependent mechanism [52]. Furthermore, the blockade of ischemia-induced GSK-3 $\beta$ inactivation via the inhibition of the PI3-K or of IGF-1 receptor reverses the phosphorylation of GSK-3 $\beta$ at its serine 9 residue [53]. Thus, IGF-1/GSK-3 $\beta$ signaling might be critical for ischemia-induced neuronal hyperproliferation in the hippocampal dentate gyrus region. These findings imply that the IGF-1-dependent $\mathrm{PI} 3-\mathrm{K} / \mathrm{Akt} / \mathrm{GSK}-3 \beta / \beta$-catenin signaling pathway is closely related to ischemia-induced neurogenesis. Interestingly, we demonstrated significant decreases in the level of IGF1 on day 7 after cerebral ischemia, when the phosphorylation state of GSK-3 $\beta$ was at its maximum. It was also shown earlier that BDNF expression and neurogenesis in the hippocampus of depressive model animals are decreased [54, 55]. Moreover, infusion of BDNF into the hippocampus of these animals improves their depressive behavior and increases neurogenesis [56, 57]. Therefore, changes in the expression of BDNF are important as underlying determinants of depressive behavior and adult neurogenesis. We demonstrated previously that intravenous injection of NPCs on day 7 after ME improves post-stroke depression-like behaviors on day 28 after ME [29]. Also, the injection of NPCs inhibits the decrease in the level of BDNF after ME [29]. Interestingly, injected NPCs are maintained in an undifferentiated condition and 
might function as cells producing neurotrophic factors [29]. In the present study, the level of BDNF was rather decreased on day 7 after ME, when endogenous proliferation was at its maximum. It is well recognized that BDNF is involved in leaning and memory function, neuroprotection and/or repair, as well as in also neurite outgrowth. Although increased levels of BDNF after cerebral ischemia have been reported [58], it has been also demonstrated that the expression level of BDNF, as well as IGF, protein is significantly decreased compared with that in the appropriate control group in well-established stroke models such as the MCAO model [59-61]. Our results in the current study and previous study [29] are consistent with the latter findings. The decrease in the protein level of BDNF appears to be associated with injured brain regions, such as between ischemic penumbra and core, and the severity of ischemic models. Although cellular sources of IGF-1 and BDNF are still not clear, our results imply that the levels of IGF-1 and BDNF in NPCs per se and/or their focal concentrations around the NPCs might be critical for improving ischemic injuries. Although neurogenesis is coordinately regulated by several factors, our findings imply that an IGF-1- and/or BDNFindependent PI3-K/Akt/GSK-3 $\beta$ pathway was enhanced by cerebral ischemia. In this sense, it is interesting that ethosuximide, an anticonvulsant drug, induces NSC proliferation and differentiation associated with increased phosphorylation of PI3-K, Akt, and GSK-3 $\beta$ and decreased phosphorylation of $\beta$-catenin, suggesting that the PI3-K/Akt/GSK-3 $\beta$ pathway had been enhanced [62].

In conclusion, as evidence of one of the endogenous regeneration abilities after cerebral ischemia, the number of NeuroD-positive cells was increased compared with that in the sham group on day 7 after surgery. It is noteworthy that the PI3-K/Akt-dependent GSK-3 $\beta$ signaling pathway was involved in the expression of NeuroD, which underlies cerebral ischemia-induced neurogenesis. Furthermore, IGF-1 and BDNF might not be essential for activation of this pathway after severe cerebral ischemia. Although it remains to be determined what factors activated this pathway, the present study provides evidence that PI3-K/Akt-dependent GSK-3 $\beta$ signaling was involved in neurogenesis after ME. Whereas future studies will be needed to determine changes in GSK-3 $\beta$ phosphorylation of specific areas in the ipsilateral hemisphere, it is possible that enhancement of GSK-3 $\beta$ phosphorylation was not maintained due to the severe ischemic condition and that repair mechanisms after ME might not be exerted completely. As ischemia-induced neurogenesis did not repair the severe cell and tissue damages, selective and focal enhancement of GSK- $3 \beta / \beta$-catenin pathways might be needed as therapy for ischemic injuries.
Acknowledgements This research was supported in part by the Takeda Science Foundation.

Compliance with Ethical Standards The study was approved by the Committee of Animal Care and Welfare of Tokyo University of Pharmacy and Life Sciences.

Conflicts of Interest The authors declare that they have no conflicts of interest.

Open Access This article is distributed under the terms of the Creative Commons Attribution 4.0 International License (http:// creativecommons.org/licenses/by/4.0/), which permits unrestricted use, distribution, and reproduction in any medium, provided you give appropriate credit to the original author(s) and the source, provide a link to the Creative Commons license, and indicate if changes were made.

\section{References}

1. Wang Y, Roach PJ (1993) Inactivation of rabbit muscle glycogen synthase by glycogen synthase kinase-3. Dominant role of the phosphorylation of Ser-640 (site-3a). J Biol Chem 268(32): 23876-23880

2. Yu JM, Kim JH, Song GS, Jung JS (2006) Increase in proliferation and differentiation of neural progenitor cells isolated from postnatal and adult mice brain by Wnt-3a and Wnt-5a. Mol Cell Biochem 288(1-2):17-28. doi:10.1007/s11010-005-9113-3

3. Adachi K, Mirzadeh Z, Sakaguchi M, Yamashita T, Nikolcheva T, Gotoh Y, Peltz G, Gong L et al (2007) Betacatenin signaling promotes proliferation of progenitor cells in the adult mouse subventricular zone. Stem Cells 25(11):28272836. doi:10.1634/stemcells.2007-0177

4. Lie DC, Colamarino SA, Song HJ, Desire L, Mira H, Consiglio A, Lein ES, Jessberger $\mathrm{S}$ et al (2005) Wnt signalling regulates adult hippocampal neurogenesis. Nature 437(7063):1370-1375. doi:10.1038/nature04108

5. Hirabayashi $\mathrm{Y}$, Itoh $\mathrm{Y}$, Tabata $\mathrm{H}$, Nakajima $\mathrm{K}$, Akiyama $\mathrm{T}$, Masuyama N, Gotoh Y (2004) The Wnt/beta-catenin pathway directs neuronal differentiation of cortical neural precursor cells. Development 131(12):2791-2801. doi:10.1242/dev.01165

6. Schuller U, Rowitch DH (2007) Beta-catenin function is required for cerebellar morphogenesis. Brain Res 1140:161-169. doi:10.1016/j.brainres.2006.05.105

7. Chae JH, Stein GH, Lee JE (2004) NeuroD: the predicted and the surprising. Mol Cells 18(3):271-288

8. Miyata T, Maeda T, Lee JE (1999) NeuroD is required for differentiation of the granule cells in the cerebellum and hippocampus. Genes Dev 13(13):1647-1652

9. Kuwabara T, Hsieh J, Muotri A, Yeo G, Warashina M, Lie DC, Moore L, Nakashima K et al (2009) Wnt-mediated activation of NeuroD1 and retro-elements during adult neurogenesis. Nat Neurosci 12(9):1097-1105. doi:10.1038/nn.2360

10. Gao Z, Ure K, Ables JL, Lagace DC, Nave KA, Goebbels S, Eisch AJ, Hsieh J (2009) Neurod1 is essential for the survival and maturation of adult-born neurons. Nat Neurosci 12(9):1090-1092. doi: $10.1038 / \mathrm{nn} .2385$

11. Roybon L, Hjalt T, Stott S, Guillemot F, Li JY, Brundin P (2009) Neurogenin2 directs granule neuroblast production and amplification while NeuroD1 specifies neuronal fate during hippocampal neurogenesis. PLoS One 4(3):e4779. doi:10.1371/journal. pone. 0004779 
12. Deisseroth K, Singla S, Toda H, Monje M, Palmer TD, Malenka RC (2004) Excitation-neurogenesis coupling in adult neural stem/ progenitor cells. Neuron 42(4):535-552

13. Tozuka Y, Fukuda S, Namba T, Seki T, Hisatsune T (2005) GABAergic excitation promotes neuronal differentiation in adult hippocampal progenitor cells. Neuron 47(6):803-815. doi:10.1016/j.neuron.2005.08.023

14. Altman J, Das GD (1965) Post-natal origin of microneurones in the rat brain. Nature 207(5000):953-956

15. Bennett L, Yang M, Enikolopov G, Iacovitti L (2009) Circumventricular organs: a novel site of neural stem cells in the adult brain. Mol Cell Neurosci 41(3):337-347. doi:10.1016/j. men.2009.04.007

16. Lin R, Cai J, Nathan C, Wei X, Schleidt S, Rosenwasser R, Iacovitti L (2015) Neurogenesis is enhanced by stroke in multiple new stem cell niches along the ventricular system at sites of high BBB permeability. Neurobiol Dis 74:229-239. doi:10.1016/j. nbd.2014.11.016

17. Zhao M, Momma S, Delfani K, Carlen M, Cassidy RM, Johansson CB, Brismar H, Shupliakov O et al (2003) Evidence for neurogenesis in the adult mammalian substantia nigra. Proc Natl Acad Sci U S A 100(13):7925-7930. doi:10.1073/pnas.1131955100

18. Alonso M, Lepousez G, Sebastien W, Bardy C, Gabellec MM, Torquet N, Lledo PM (2012) Activation of adult-born neurons facilitates learning and memory. Nat Neurosci 15(6):897-904. doi:10.1038/nn.3108

19. Santarelli L, Saxe M, Gross C, Surget A, Battaglia F, Dulawa S, Weisstaub N, Lee J et al (2003) Requirement of hippocampal neurogenesis for the behavioral effects of antidepressants. Science 301(5634):805-809. doi:10.1126/science.1083328

20. Arvidsson A, Collin T, Kirik D, Kokaia Z, Lindvall O (2002) Neuronal replacement from endogenous precursors in the adult brain after stroke. Nat Med 8(9):963-970

21. Kernie SG, Parent JM (2010) Forebrain neurogenesis after focal ischemic and traumatic brain injury. Neurobiol Dis 37(2):267274. doi:10.1016/j.nbd.2009.11.002

22. Liu J, Solway K, Messing RO, Sharp FR (1998) Increased neurogenesis in the dentate gyrus after transient global ischemia in gerbils. J Neurosci 18(19):7768-7778

23. Nakatomi H, Kuriu T, Okabe S, Yamamoto S, Hatano O, Kawahara N, Tamura A, Kirino T et al (2002) Regeneration of hippocampal pyramidal neurons after ischemic brain injury by recruitment of endogenous neural progenitors. Cell 110(4):429-441

24. Yamashita T, Ninomiya M, Hernandez Acosta P, Garcia-Verdugo JM, Sunabori T, Sakaguchi M, Adachi K, Kojima T et al (2006) Subventricular zone-derived neuroblasts migrate and differentiate into mature neurons in the post-stroke adult striatum. J Neurosci 26(24):6627-6636. doi:10.1523/JNEUROSCI.0149-06.2006

25. Toda H, Tsuji M, Nakano I, Kobuke K, Hayashi T, Kasahara H, Takahashi J, Mizoguchi A et al (2003) Stem cell-derived neural stem/progenitor cell supporting factor is an autocrine/paracrine survival factor for adult neural stem/progenitor cells. J Biol Chem 278(37):35491-35500. doi:10.1074/jbc.M305342200

26. Gu YL, Yin LW, Zhang Z, Liu J, Liu SJ, Zhang LF, Wang TH (2012) Neurotrophin expression in neural stem cells grafted acutely to transected spinal cord of adult rats linked to functional improvement. Cell Mol Neurobiol 32(7):1089-1097. doi:10.1007/s10571012-9832-4

27. He BL, Ba YC, Wang XY, Liu SJ, Liu GD, Ou S, Gu YL, Pan XH et al (2013) BDNF expression with functional improvement in transected spinal cord treated with neural stem cells in adult rats. Neuropeptides 47(1):1-7. doi:10.1016/j.npep.2012.06.001

28. Mochizuki N, Takagi N, Kurokawa K, Onozato C, Moriyama Y, Tanonaka K, Takeo S (2008) Injection of neural progenitor cells improved learning and memory dysfunction after cerebral ischemia. Exp Neurol 211(1):194-202
29. Moriyama Y, Takagi N, Tanonaka K (2011) Intravenous injection of neural progenitor cells improved depression-like behavior after cerebral ischemia. Transl Psychiatry 1:e29. doi:10.1038/tp.2011.32

30. Moriyama Y, Takagi N, Itokawa C, Tanonaka K (2013) Injection of neural progenitor cells attenuates decrease in level of connexin 43 in brain capillaries after cerebral ischemia. Neurosci Lett 543:152156. doi:10.1016/j.neulet.2013.03.053

31. Kajihara H, Tsutsumi E, Kinoshita A, Nakano J, Takagi K, Takeo S (2001) Activated astrocytes with glycogen accumulation in ischemic penumbra during the early stage of brain infarction: immunohistochemical and electron microscopic studies. Brain Res 909(12):92-101

32. Miyake K, Takeo S, Kaijihara H (1993) Sustained decrease in brain regional blood flow after microsphere embolism in rats. Stroke 24(3):415-420

33. Stoyanova S, Bulgarelli-Leva G, Kirsch C, Hanck T, Klinger R, Wetzker R, Wymann MP (1997) Lipid kinase and protein kinase activities of G-protein-coupled phosphoinositide 3-kinase gamma: structure-activity analysis and interactions with wortmannin. Biochem J 324(Pt 2):489-495

34. Krafft PR, Altay O, Rolland WB, Duris K, Lekic T, Tang J, Zhang JH (2012) alpha7 nicotinic acetylcholine receptor agonism confers neuroprotection through GSK-3beta inhibition in a mouse model of intracerebral hemorrhage. Stroke 43(3):844-850. doi:10.1161/STROKEAHA.111.639989

35. Wen XR, Fu YY, Liu HZ, Wu J, Shao XP, Zhang XB, Tang M, Shi $Y$ et al (2016) Neuroprotection of sevoflurane against ischemia/ reperfusion-induced brain injury through inhibiting JNK3/ caspase- 3 by enhancing Akt signaling pathway. Mol Neurobiol 53(3):1661-1671. doi:10.1007/s12035-015-9111-8

36. Cross DA, Alessi DR, Cohen P, Andjelkovich M, Hemmings BA (1995) Inhibition of glycogen synthase kinase- 3 by insulin mediated by protein kinase B. Nature 378(6559):785-789. doi: $10.1038 / 378785 \mathrm{a} 0$

37. Mochizuki N, Takagi N, Onozato C, Moriyama Y, Takeo S, Tanonaka K (2008) Delayed injection of neural progenitor cells improved spatial learning dysfunction after cerebral ischemia. Biochem Biophys Res Commun 368(1):151-156

38. Moriyama Y, Takagi N, Hashimura K, Itokawa C, Tanonaka K (2013) Intravenous injection of neural progenitor cells facilitates angiogenesis after cerebral ischemia. Brain and Behavior 3(2):4353. doi: $10.1002 /$ brb3.113

39. Cowper-Smith CD, Anger GJ, Magal E, Norman MH, Robertson GS (2008) Delayed administration of a potent cyclin dependent kinase and glycogen synthase kinase 3 beta inhibitor produces long-term neuroprotection in a hypoxia-ischemia model of brain injury. Neuroscience 155(3):864-875. doi:10.1016/j. neuroscience.2008.05.051

40. Sasaki C, Hayashi T, Zhang WR, Warita H, Manabe Y, Sakai K, Abe K (2001) Different expression of glycogen synthase kinase-3beta between young and old rat brains after transient middle cerebral artery occlusion. Neurol Res 23(6):588-592. doi:10.1179/016164101101199054

41. Hur EM, Zhou FQ (2010) GSK3 signalling in neural development. Nat Rev Neurosci 11(8):539-551. doi:10.1038/nrn2870

42. Morales-Garcia JA, Luna-Medina R, Alonso-Gil S, SanzSancristobal M, Palomo V, Gil C, Santos A, Martinez A et al (2012) Glycogen synthase kinase 3 inhibition promotes adult hippocampal neurogenesis in vitro and in vivo. ACS Chem Neurosci 3(11):963-971. doi:10.1021/cn300110c

43. Chen G, Rajkowska G, Du F, Seraji-Bozorgzad N, Manji HK (2000) Enhancement of hippocampal neurogenesis by lithium. J Neurochem 75(4):1729-1734

44. Kawai T, Takagi N, Miyake-Takagi K, Okuyama N, Mochizuki N, Takeo S (2004) Characterization of BrdUpositive neurons induced by transient global ischemia in adult 
hippocampus. J Cereb Blood Flow Metab 24(5):548-555. doi:10.1097/00004647-200405000-00009

45. Naya FJ, Huang HP, Qiu Y, Mutoh H, DeMayo FJ, Leiter AB, Tsai MJ (1997) Diabetes, defective pancreatic morphogenesis, and abnormal enteroendocrine differentiation in BETA2/neuroD-deficient mice. Genes Dev 11(18):2323-2334

46. Kim WY (2013) NeuroD regulates neuronal migration. Mol Cells 35(5):444-449. doi:10.1007/s10059-013-0065-2

47. Cameron HA, Hazel TG, McKay RD (1998) Regulation of neurogenesis by growth factors and neurotransmitters. J Neurobiol 36(2):287-306

48. Chao J, Yang L, Yao H, Buch S (2014) Platelet-derived growth factor-BB restores HIV tat -mediated impairment of neurogenesis: role of GSK-3beta/beta-catenin. J NeuroImmune Pharmacol 9(2): 259-268. doi:10.1007/s11481-013-9509-x

49. O'Kusky JR, Ye P, D'Ercole AJ (2000) Insulin-like growth factor-I promotes neurogenesis and synaptogenesis in the hippocampal dentate gyrus during postnatal development. J Neurosci 20(22):8435-8442

50. O'Kusky J, Ye P (2012) Neurodevelopmental effects of insulin-like growth factor signaling. Front Neuroendocrinol 33(3):230-251. doi:10.1016/j.yfrne.2012.06.002

51. Nieto-Estevez V, Defterali C, Vicario-Abejon C (2016) IGF-I: a key growth factor that regulates neurogenesis and synaptogenesis from embryonic to adult stages of the brain. Front Neurosci 10:52. doi:10.3389/fnins.2016.00052

52. Fukushima T, Nakamura Y, Yamanaka D, Shibano T, Chida K, Minami S, Asano T, Hakuno F et al (2012) Phosphatidylinositol 3-kinase (PI3K) activity bound to insulin-like growth factor-I (IGFI) receptor, which is continuously sustained by IGF-I stimulation, is required for IGF-I-induced cell proliferation. J Biol Chem 287(35): 29713-29721. doi:10.1074/jbc.M112.393074

53. Kim DH, Lee HE, Kwon KJ, Park SJ, Heo H, Lee Y, Choi JW, Shin CY et al (2015) Early immature neuronal death initiates cerebral ischemia-induced neurogenesis in the dentate gyrus. Neuroscience 284:42-54. doi:10.1016/j.neuroscience.2014.09.074

54. Smith MA, Makino S, Kvetnansky R, Post RM (1995) Stress and glucocorticoids affect the expression of brain-derived neurotrophic factor and neurotrophin-3 mRNAs in the hippocampus. J Neurosci 15(3 Pt 1):1768-1777

55. Malberg JE, Duman RS (2003) Cell proliferation in adult hippocampus is decreased by inescapable stress: reversal by fluoxetine treatment. Neuropsychopharmacology 28(9):1562-1571. doi:10.1038/sj.npp.1300234

56. Shirayama Y, Chen AC, Nakagawa S, Russell DS, Duman RS (2002) Brain-derived neurotrophic factor produces antidepressant effects in behavioral models of depression. J Neurosci 22(8):3251-3261

57. Scharfman H, Goodman J, Macleod A, Phani S, Antonelli C, Croll $\mathrm{S}$ (2005) Increased neurogenesis and the ectopic granule cells after intrahippocampal BDNF infusion in adult rats. Exp Neurol 192(2): 348-356. doi:10.1016/j.expneurol.2004.11.016

58. Liu B, Li LL, Tan XD, Zhang YH, Jiang Y, He GQ, Chen Q, Li CQ (2015) Gadd45b mediates axonal plasticity and subsequent functional recovery after experimental stroke in rats. Mol Neurobiol 52(3):1245-1256. doi:10.1007/s12035-014-8909-0

59. Li X, Zheng W, Bai H, Wang J, Wei R, Wen H, Ning H (2016) Intravenous administration of adipose tissue-derived stem cells enhances nerve healing and promotes BDNF expression via the TrkB signaling in a rat stroke model. Neuropsychiatr Dis Treat 12:12871293. doi:10.2147/NDT.S104917

60. Gutierrez-Vargas JA, Munera A, Cardona-Gomez GP (2015) CDK5 knockdown prevents hippocampal degeneration and cognitive dysfunction produced by cerebral ischemia. J Cereb Blood Flow Metab 35(12):1937-1949. doi:10.1038/jcbfm.2015.150

61. Chang HC, Yang YR, Wang PS, Kuo CH, Wang RY (2013) The neuroprotective effects of intramuscular insulin-like growth factor-I treatment in brain ischemic rats. PLoS One 8(5):e64015. doi:10.1371/journal.pone.0064015

62. Tiwari SK, Seth B, Agarwal S, Yadav A, Karmakar M, Gupta SK, Choubey V, Sharma A et al (2015) Ethosuximide induces hippocampal neurogenesis and reverses cognitive deficits in an amyloidbeta toxin-induced Alzheimer rat model via the phosphatidylinositol 3-kinase (PI3K)/Akt/Wnt/beta-catenin pathway. J Biol Chem 290(47):28540-28558. doi:10.1074/jbc.M115.652586 